\title{
Cognitive Impairment Is the Major Risk Factor for Development of Geriatric Syndromes during Hospitalization: Results from the GIFA Study
}

\author{
Patrizia Mecocci $^{\mathrm{a}}$ Eva von Strauss ${ }^{\mathrm{b}}$ Antonio Cherubini ${ }^{\mathrm{a}}$ Sara Ercolani $^{\mathrm{a}}$ \\ Elena Mariani $^{\mathrm{a}}$ Umberto Senin $^{\mathrm{a}}$ Bengt Winblad $^{\mathrm{b}}$ Laura Fratiglioni ${ }^{\mathrm{b}}$ \\ for the GIFA Study Group \\ ${ }^{a}$ Institute of Gerontology and Geriatrics, Department of Clinical and Experimental Medicine, University of \\ Perugia, Perugia, Italy, ${ }^{\mathrm{b}}$ Aging Research Center, Division of Geriatric Epidemiology and Medicine, Neurotec, \\ Karolinska Institutet, Stockholm, Sweden
}

\section{Key Words}

Cognitive impairment · Elderly · Hospitalization ·

Geriatric syndromes $\cdot$ Risk factor

\begin{abstract}
Objective: To detect the main factors associated with the occurrence of specific geriatric syndromes (namely pressure sores, fecal incontinence, urinary incontinence and falls) in elderly patients during hospitalization. Design: Observational prospective study. Setting: Eighty-one community and university hospitals throughout Italy. Participants: 13,729 patients aged 65 years and more, consecutively admitted to medical or geriatric acute wards during 20 months in the period between 1991 and 1998. Measurements: Occurrence of pressure sores, fecal incontinence, urinary incontinence and falls during the stay in hospital. Results: Pressure sores were already present in $3 \%$ of hospitalized subjects, fecal incontinence in $7.3 \%$, while urinary incontinence, evaluated on a subgroup of total population $(4,268$ subjects), had a prevalence of $22.3 \%$. During hospitalization (mean stay of 15 days), 74 subjects developed new pressure sores, 55 became fecal and 35 urinary incontinent, and 279 subjects had at least one episode of fall. In
\end{abstract}

GIFA Study Group investigators are listed in European Journal of Epidemiology 1999;15:893-901.
(C) 2005 S. Karger AG, Basel

$1420-8008 / 05 / 0204-0262 \$ 22.00 / 0$

Fax +4161306 1234 E-Mail karger@karger.ch www.karger.com www.karger.com/dem multivariate analyses, cognitive impairment, advanced age (85+ years), length of stay (more than 3 weeks) and severe disability were the main independent predictors of development of the four geriatric syndromes, with cognitive impairment as the most significant risk factor for all the four outcomes (OR 4.9, 95\% Cl 2.4-9.9 for pressure sores; OR $6.3,95 \% \mathrm{Cl} 3.0-13.0$ for fecal incontinence; OR $5.3,95 \% \mathrm{Cl} 2.3-12.0$ for urinary incontinence; OR 1.6, 95\% Cl 1.2-2.3 for falls). Conclusion: Very old people have a significant increased risk of several geriatric syndromes during the stay in hospital, particularly if it is long and they are cognitively impaired. A standardized comprehensive geriatric evaluation at admission could be helpful in detecting all subjects at risk and preventing the development of hospital-acquired geriatric syndromes.

Copyright (C) 2005 S. Karger AG, Basel

\section{Introduction}

Aging of the population in Western countries undoubtedly represents the main result of better social and medical conditions during the last century but, in the meantime, also the greatest challenge for the health system since the increasing number of chronic diseases and subsequent disability are going to request a different approach in the treatment and care of the elderly.

Patrizia Mecocci, MD, $\mathrm{PhD}$

Institute of Gerontology and Geriatrics, Department of Clinical and Experimental

Medicine, University of Perugia, Policlinico Monteluce-Padiglione E, via Brunamonti 51

IT-06122 Perugia (Italy)

Tel. +39075 578 3270, Fax +39075 573 0259, E-Mail mecocci@unipg.it 
Hospital is still the major site of health provision for the elderly [1], although its role in the health system is the treatment of acute diseases. The discrepancy between supply and demand can easily explain the inappropriateness of several admissions of elderly patients in acute-care hospitals and the subsequent increase in medical expenditures.

It has been shown that during hospitalization elderly subjects have a high risk of adverse events - defined as an unintended injury caused by medical management that resulted in prolongation of hospitalization or disability at discharge [2] - which can cause an irreversible decline in functional status [3], and an increased rate of placement in nursing homes after discharge [4]. The increasing age of patients admitted in the hospitals will probably increase the risk of adverse events, and a better knowledge of those aspects more associated with negative outcomes during hospitalization will be helpful in preventing medical injuries and improving the quality of care [5]. But also hospitalization per se can represent in the older population a risk for the development of severe complications related to hospital environment and hazards. These aspects, associated with an increased susceptibility to various stresses due to the aging process, often cause an irreversible decline in functional status and a change in quality and style of life after discharge [6].

In this study, we evaluated the occurrence of four typical geriatric syndromes - namely pressure sores, fecal and urinary incontinence and falls - observed in an elderly population during hospitalization. The aim was to detect the factors more associated with the risk of such injuries. Data were gathered from the Gruppo Italiano di Farmacovigilanza nell'Anziano (GIFA; Italian Group of Pharmacoepidemiology in the Elderly) study, which included a large cohort of elderly people admitted to community and university hospitals in Italy.

\section{Methods}

The GIFA study includes 81 community and university hospitals located throughout Italy and periodically surveys drug use, occurrence of adverse drug reactions and quality of hospital care [for details, see 7]. Briefly, all patients admitted to the participating hospitals during the surveillance periods (May-June and November-December, in order to control the seasonal variation of the diseases) in different years (1991, 1993, 1995, 1997 and 1998) were enrolled in the study and followed until discharge or death. For each patient a questionnaire was completed at admission and updated daily by a study physician who had received specific training. Data were recorded using a dedicated software; the variables recorded included demographic characteristics, objective tests and measures, drugs taken before admission, during hospital stay and at discharge, diagnosis at admission and discharge, history of falls and evaluation of comorbidity, cognitive function, functional status, quality of care.

Sociodemographic variables included age, gender, years of education, marital status and place of residence. Length of hospitalization was also registered.

Cognitive status was assessed by means of the Hodkinson's Abbreviated Mental Test (AMT) [8], a 10-item version of the BlessedRoth information memory concentration test, whose total score ranges from 0 (no correct answer) to 10 (all correct answers). The AMT has been validated in Italy and a score of less than 7 was the best combination of sensitivity and specificity to detect dementia [9]. Thus, subjects with a score lower than 7 were considered as cognitively impaired.

Clinical diagnoses were made on the basis of direct clinical evaluation and laboratory and instrumental findings by the ward physicians. Diseases were coded according to ICD-9. Total number of diseases identified in the chart record were also computed. To evaluate the effect of specific diseases on the different selected outcomes, we took into account the following pathologies or group of pathologies: cardiovascular diseases (coronary disease, hypertension, heart failure and atrial fibrillation), cerebrovascular diseases, chronic obstructive pulmonary disease, tumors, fractures, diabetes, severe hepatic and renal diseases. To quantify comorbidity, we used the number of diseases as well as the Charlson comorbidity index [10], which is a weighted index of comorbidity that takes into account the number and the severity of health problems present in a subject.

Functional status was assessed on the basis of six activities of daily living (ADL) exploring the following functions: transferring from bed to chair, walking, dressing, eating, toileting and bathing. Score ranged from 0 (complete independence) to 6 (total dependency).

Drugs were coded according to the anatomical therapeutic and chemical codes. Although several drugs can contribute to one or more of the four geriatric syndromes selected as the main outcomes of this study (see below), we analyzed only the influence of central nervous system (CNS) active drugs, including antiepileptics, antiparkinson, neuroleptics, benzodiazepines and antidepressants (anatomical therapeutic and chemical codes N03, N04, N05A, N05B, N05C, N06A), that have a well-established impact on the occurrence of all of them.

The outcomes selected for the study were the occurrence - defined as absence at admission and presence at discharge - of specific events (pressure sores, fecal incontinence, urinary incontinence, falls) during hospitalization.

Pressure sores were staged on a 4-point scale [11]. Development of a pressure sore was defined as absence or presence of one stage 1 pressure ulcer at admission, and presence of almost one pressure ulcer of stage 2-4 at discharge. Occurrence of fecal and urinary incontinence was defined as absence at admission and presence at discharge being data of bowel and bladder continence registered in patient's chart record. Unfortunately, since urinary incontinence was differently registered in the different years of survey, only data from the years 1991 and 1998 were suited to the purpose of this study. Fall was defined as an unintentional change in position from a lying, sitting or standing position resulting in coming to rest on the ground or on some other lower level. A trained physician ascertained falls both from daily patient interviews and from reviews of nursing charts and medical records. 
Table 1. Characteristics of the population at admission

\begin{tabular}{llll}
\hline & Total & Men & Women \\
\hline Patients & 13,729 & $6,426(46.8 \%)$ & $7,303(53.2 \%)$ \\
Age, years & $78.3 \pm 7.2$ & $77.2 \pm 7.0$ & $79.2 \pm 7.3$ \\
$\quad 65-74, \%$ & 31.5 & 37.3 & 26.4 \\
$75-84, \%$ & 44.9 & 43.6 & 46.0 \\
$\quad 285, \%$ & 23.6 & 19.1 & 27.6 \\
Education, years & $5.3 \pm 3.4$ & $5.9 \pm 3.8$ & $4.7 \pm 2.9$ \\
Single, \% & 43.3 & 22.9 & 61.7 \\
Living alone, \% & 20.8 & 12.7 & 28.0 \\
ADL & $4.15 \pm 2.5$ & $4.39 \pm 2.4$ & $3.95 \pm 2.5$ \\
$\quad$ Totally independent $(0), \%$ & 58.0 & 62.6 & 53.9 \\
$\quad$ Partially independent (1-5), \% & 22.7 & 20.2 & 25.0 \\
Totally dependent (6), \% & 19.3 & 17.2 & 21.1 \\
AMT score & $7.01 \pm 3.0$ & $7.43 \pm 2.9$ & $6.66 \pm 3.1$ \\
$\quad$ Cognitive impairment ${ }^{1}, \%$ & 27.0 & 22.2 & 30.2 \\
Number of diseases & $3.9 \pm 2.2$ & $3.8 \pm 2.1$ & $3.9 \pm 2.2$ \\
Charlson index & $1.7 \pm 1.7$ & $1.8 \pm 1.8$ & $1.5 \pm 1.6$ \\
0, \% & 26.3 & 23.2 & 29.1 \\
1-2, \% & 49.1 & 48.9 & 49.3 \\
$\quad \geq 3, \%$ & 24.6 & 27.9 & 21.6 \\
Pressure sores, \% & 3.0 & 2.8 & 3.2 \\
Fecal incontinence, \% & 7.3 & 5.9 & 8.6 \\
Urinary incontinence, \% of 4,268 patients & 22.3 & 19.9 & 24.5 \\
\hline
\end{tabular}

Results are presented as mean \pm SD except where otherwise stated.

${ }^{1} \mathrm{AMT}<7$.
Data of 15,711 patients aged $\geq 65$ years were found in the dataset. Subjects who died during the hospital stay and those lacking an AMT score (920 men, mean age $77.4 \pm 7.1$, and 1,062 women, mean age $79.6 \pm 7.1$ ) were excluded. Their demographic characteristics did not differ from the evaluated population. A total of 13,729 patients, 6,426 men and 7,303 women, was considered.

Data of continuous variables are presented as mean \pm 1 standard deviation (SD). Statistical analyses were performed using SPSS for Windows 11.5 software (Chicago, Ill., USA); differences were considered significant at $\mathrm{p}<0.05$. Analyses of continuous variables were performed with Student's t test or ANOVA and posthoc Bonferroni test as needed. $\chi^{2}$ analysis and Fisher exact test were used for dichotomous variables.

Logistic regression analysis was used to estimate the association of variables of interest with the different dependent variables of the study, i.e. occurrence during hospitalization of (1) pressure sores, (2) fecal incontinence, (3) urinary incontinence and (4) falls. Odds ratio (OR) and 95\% confidence interval (CI) were calculated. All independent variables were first evaluated as continuous variables and, if they were significantly associated with any of the selected outcomes, they entered the model also as categorical variables. Age was categorized into three groups $(65-74,75-84, \geq 85$ years), to detect possible differential findings in young-old, old-old and oldest-old subjects [12]. Number of diseases was categorized according to the quartile distribution $(1-2,3-4,5-6, \geq 7)$. Charlson index was analyzed first by using quartiles of the distribution, then by grouping the second and the third group together due to their similar effects on the four different outcomes. Number of drugs prescribed during hospitalization was categorized according to the quartile distribution ( $\leq 3,4-6,7-9, \geq 10)$. A more detailed analysis was subsequently performed on CNS active drugs. Total length of stay was divided in tertiles ( $\leq 2$ weeks; $\leq 3$ weeks; $>3$ weeks). ADL at admission was grouped according to the functional status in totally independent $(\mathrm{ADL}$ score $=0)$, partially dependent $(\mathrm{ADL}$ score $=$ $1-5)$ and totally dependent (ADL score $=6$ ) persons.

First, a bivariate analysis was performed, in which each factor was evaluated in relation to the four outcomes by using separate logistic regression models, including the demographic variables (age, gender and education). Then the significantly associated factors were further investigated to verify their independent effect by using two multi-adjusted logistic regression models. The first model aimed at finding which diseases were associated with the risk of development of each event; the second model was constructed to evaluate the global effect of comorbidity by using the Charlson index. All factors were entered into a stepwise backward logistic regression analysis after gender, age and educational level adjustment. Only significant results are reported.

\section{Results}

The main characteristics of the studied population at admission are reported in table 1 . Women were older, less educated, more functionally and cognitively impaired than men, but with a lower level of comorbidity index. 
Table 2. Diseases associated with the occurrence of geriatric syndromes during hospitalization

\begin{tabular}{lclll}
\hline & Pressure sores & $\begin{array}{l}\text { Fecal } \\
\text { incontinence }\end{array}$ & $\begin{array}{l}\text { Urinary } \\
\text { incontinence }\end{array}$ & Falls \\
\hline Cognitive impairment & $10.1(5.3-19.1)$ & $9.6(5.0-18.5)$ & $7.5(3.5-15.9)$ & $1.9(1.4-2.5)$ \\
Cardiovascular diseases & $1.1(0.6-2.0)$ & $1.3(0.7-2.3)$ & $0.99(0.46-2.11)$ & $0.8(0.6-1.2)$ \\
Cerebrovascular diseases & $2.5(1.4-4.2)$ & $3.7(2.1-6.4)$ & $3.3(1.6-6.8)$ & $1.7(1.3-2.3)$ \\
COPD & $0.9(0.4-2.0)$ & $0.3(0.1-1.0)$ & $0.5(0.1-1.6)$ & $0.9(0.7-1.4)$ \\
Tumor & $1.4(0.6-3.2)$ & $2.7(1.4-5.4)$ & $1.6(0.5-4.5)$ & $0.9(0.6-1.4)$ \\
Fractures & $5.8(2.6-13.1)$ & $2.6(0.8-8.4)$ & $0($ n.s. & $1.4(0.7-1.9)$ \\
Diabetes & $0($ n.e.) & $1.6(0.2-12.0)$ & $3.1(0.4-23.6)$ & $1.7(0.7-4.1)$ \\
Hepatic diseases & $0.9(0.2-3.8)$ & $1.6(0.5-5.3)$ & $0($ n.e. & $1.2(0.7-2.2)$ \\
Renal diseases & $1.5(0.6-3.7)$ & $2.7(0.7-5.7)$ & $2.6(0.9-6.9)$ & $1.1(0.7-1.8)$ \\
Number of diseases & $1.3(1.0-1.7)$ & $1.3(1.0-1.8)$ & $1.2(0.8-1.7)$ & $1.2(1.0-1.4)$ \\
History of falls & $1.2(0.6-2.4)$ & $2.9(1.6-5.2)$ & $3.2(1.5-7.0)$ & $9.2(7.0-12.0)$ \\
\hline
\end{tabular}

COPD = Chronic obstructive pulmonary disease; n.s. = not significant. Figures represent ORs (95\% CIs) adjusted for age, gender and education.

Table 3. Comorbidity, length of stay, functional impairment, number and type of drugs associated with the occurrence of geriatric syndromes during hospitalization

\begin{tabular}{|c|c|c|c|c|}
\hline & Pressure sores & $\begin{array}{l}\text { Fecal } \\
\text { incontinence }\end{array}$ & $\begin{array}{l}\text { Urinary } \\
\text { incontinence }\end{array}$ & Falls \\
\hline \multicolumn{5}{|l|}{ Charlson index } \\
\hline 0 & 1 & 1 & 1 & 1 \\
\hline $1-2$ & $2.1(0.9-4.8)$ & $3.2(0.9-11.0)$ & $1.9(0.5-6.7)$ & $1.4(0.97-2.0)$ \\
\hline$\geq 3$ & $4.1(1.8-9.8)$ & $11.7(3.6-38.5)$ & $5.1(1.5-17.6)$ & $2.0(1.4-3.0)$ \\
\hline \multicolumn{5}{|l|}{ Length of stay, weeks } \\
\hline$\leq 2$ & 1 & 1 & 1 & 1 \\
\hline$\leq 3$ & $3.6(1.8-7.5)$ & $1.5(0.7-3.3)$ & $2.2(0.8-5.7)$ & $1.6(1.1-2.2)$ \\
\hline$>3$ & $7.5(3.9-14.3)$ & $4.9(2.7-9.0)$ & $5.6(2.5-12.6)$ & $2.4(1.8-3.3)$ \\
\hline \multicolumn{5}{|l|}{$\mathrm{ADL}$} \\
\hline Totally independent $(0)$ & 1 & 1 & 1 & 1 \\
\hline Partially independent (1-5) & $4.5(1.7-12.2)$ & $2.5(1.1-5.6)$ & $2.3(0.96-5.7)$ & $1.5(1.1-2.0)$ \\
\hline Totally dependent (6) & $19.7(8.2-47.3)$ & $9.7(4.7-29.8)$ & $7.5(3.1-18.5)$ & $1.6(1.2-2.3)$ \\
\hline \multicolumn{5}{|l|}{ Number of drugs } \\
\hline $0-3$ & 1 & 1 & 1 & 1 \\
\hline $4-6$ & $2.0(0.4-8.9)$ & $1.0(0.3-4.0)$ & $1.2(0.3-4.2)$ & $1.4(0.7-2.4)$ \\
\hline $7-9$ & $2.2(0.5-9.9)$ & $1.8(0.5-6.5)$ & $0.9(0.2-3.8)$ & $1.7(0.9-2.9)$ \\
\hline$\geq 10$ & $6.3(1.5-26.4)$ & $3.1(0.9-10.2)$ & $1.5(0.4-5.4)$ & $2.7(1.6-4.7)$ \\
\hline Neuroleptics & $0.8(0.3-2.3)$ & $2.5(1.2-5.5)$ & $2.8(0.9-8.2)$ & $2.7(1.9-3.8)$ \\
\hline Benzodiazepines & $0.6(0.3-1.2)$ & $0.6(0.3-1.4)$ & $0.3(0.1-1.4)$ & $1.9(1.5-2.6)$ \\
\hline Antidepressants & $0.6(0.2-2.1)$ & $1.8(0.7-4.2)$ & $0.5(0.1-3.4)$ & $2.3(0.6-3.2)$ \\
\hline Antiepileptics & $2.0(0.7-5.6)$ & $2.5(0.9-6.9)$ & $1.6(0.4-6.9)$ & $1.6(0.9-2.8)$ \\
\hline Antiparkinson drugs & $2.0(0.7-2.5)$ & $2.6(1.3-11.5)$ & $2.3(0.8-9.5)$ & $1.5(0.8-2.5)$ \\
\hline
\end{tabular}

Figures represent ORs (95\% CIs) adjusted for age, gender and education. 
Table 4. Factors independently related to the occurrence of geriatric syndromes during hospitalization

\begin{tabular}{|c|c|c|c|c|}
\hline & Pressure sores & $\begin{array}{l}\text { Fecal } \\
\text { incontinence }\end{array}$ & $\begin{array}{l}\text { Urinary } \\
\text { incontinence }\end{array}$ & Falls \\
\hline Gender & $1.5(0.8-2.7)$ & $0.9(0.3-1.7)$ & $0.6(0.3-1.4)$ & $0.8(0.6-1.3)$ \\
\hline \multicolumn{5}{|l|}{ Age, years } \\
\hline $65-74$ & 1 & 1 & 1 & 1 \\
\hline $75-84$ & $2.0(0.8-5.0)$ & $2.4(0.2-6.6)$ & $1.9(0.6-5.4)$ & $1.5(1.0-2.2)$ \\
\hline$\geq 85$ & $2.3(0.9-5.8)$ & $3.7(1.4-10.2)$ & $3.2(1.1-9.8)$ & $1.8(1.2-2.8)$ \\
\hline Cognitive impairment & $4.9(2.4-9.9)$ & $6.3(3.0-13.0)$ & $5.3(2.3-12.0)$ & $1.6(1.2-2.3)$ \\
\hline Cerebrovascular diseases & $1.3(0.7-2.2)$ & $2.4(1.3-4.4)$ & $2.4(1.1-5.3)$ & $1.4(1.0-1.9)$ \\
\hline Tumors & $1.5(0.6-3.3)$ & $3.4(1.7-7.1)$ & $1.6(0.5-5.3)$ & $0.9(0.5-1.5)$ \\
\hline Fractures & $3.0(1.3-7.1)$ & $1.4(0.4-4.9)$ & $0.01(\mathrm{ne})$ & $1.5(0.7-2.2)$ \\
\hline History of falls & - & - & - & $8.1(6.1-10.8)$ \\
\hline Neuroleptics & $0.3(0.1-1.2)$ & $1.2(0.5-2.6)$ & $1.4(0.4-4.9)$ & $2.1(1.4-3.0)$ \\
\hline Benzodiazepines & $0.8(0.4-1.8)$ & $0.7(0.3-1.6)$ & $0.4(0.1-1.7)$ & $1.9(1.4-2.5)$ \\
\hline \multicolumn{5}{|l|}{ Length of stay, weeks } \\
\hline$\leq 2$ & 1 & 1 & 1 & 1 \\
\hline$\leq 3$ & $3.5(1.7-7.3)$ & $1.5(0.7-3.4)$ & $2.1(0.8-5.7)$ & $1.6(1.2-2.3)$ \\
\hline$>3$ & $6.3(3.3-12.2)$ & $4.4(2.3-8.3)$ & $6.5(2.8-15.5)$ & $2.4(1.7-3.3)$ \\
\hline \multicolumn{5}{|l|}{ ADL } \\
\hline Totally independent $(0)$ & 1 & 1 & 1 & 1 \\
\hline Partially independent (1-5) & $2.5(0.9-6.8)$ & $1.3(0.5-3.0)$ & $1.6(0.6-3.9)$ & $0.8(0.6-1.1)$ \\
\hline Totally dependent (6) & $8.4(3.2-21.5)$ & $2.5(1.1-5.5)$ & $2.9(1.1-7.6)$ & $0.7(0.5-1.1)$ \\
\hline
\end{tabular}

Figures represent multiadjusted ORs (95\% CIs). Significant values are in bold type.

More often they were single (mostly widows) and lived alone. At entrance, pressure sores were already present in $3 \%$ of the study population $(2.8 \%$ in men and $3.2 \%$ in women), fecal incontinence in $7.3 \%$ (5.9\% in men and $8.6 \%$ in women). Urinary incontinence, which was evaluated on a subgroup of 4,268 subjects, had a prevalence of $22.3 \%$ (19.9\% in men and $24.5 \%$ in women).

During the hospitalization (mean stay of 15 days), 74 subjects developed new pressure sores (cumulative incidence $0.5 \%$ ), 55 became fecal and 35 urinary incontinent (cumulative incidence 0.4 and $1 \%$, respectively), and 279 subjects had at least one episode of fall (cumulative incidence $1.9 \%$ ).

When all possible predictors of the selected outcomes were entered in separate logistic models adjusted for age, gender and education, the following factors emerged as associated with an increased risk of developing at least one of the four geriatric syndromes during hospitalization: increasing age, cognitive impairment, cerebrovascular diseases, tumors, fractures, number of diseases, history of falls, Charlson index, length of stay, functional dependence (ADL score), use of neuroleptics and benzodiazepines (tables 2 and 3). All these factors were entered in two models.
The first model tested the independent effect of single diseases, functional status and use of neuroleptics and benzodiazepines on the development of adverse events (table 4). Very advanced age, cognitive impairment as well as length of hospitalization (especially more than 3 weeks) markedly increased the risk for all the considered events. Some diseases increased the risk for specific geriatric syndromes, but not for all. Cerebrovascular diseases increased the risk of developing both fecal (OR: 2.4; 95\% CI: 1.3-4.4) and urinary incontinence (OR: $2.4 ; 95 \%$ CI: 1.1-5.3); suffering from tumors increased the risk of fecal incontinence (OR: 3.4; 95\% CI: 1.7-7.1), while fractures increased the risk of developing pressure sores (OR: 3.0; 95\% CI: 1.3-7.1). An extremely severe disability (ADL = 6) was independently associated with the development of pressure sores (OR: 8.4; 95\% CI: 3.2-21.5), fecal (OR: 2.5; 95\% CI: 1.1-5.5) and urinary incontinence (OR: 2.9; 95\% CI: 1.1-7.6), but not with falls. Factors independently associated with falls were history of previous falls (OR: 8.1; 95\% CI: 6.1-10.8) and use of neuroleptics (OR: 2.1; 95\% CI: 1.4-3.0) and benzodiazepines (OR: 1.9; 95\% CI: 1.42.5).

The second model was similar to the first one with the exception that single diseases were substituted by the 
Charlson comorbidity index. A severe comorbidity, expressed by a score of $\geq 3$ on the Charlson index, increased the risk for fecal incontinence (OR: $5.5 ; 95 \%$ CI: $1.6-$ 18.4) and for falls (OR: 1.6; 95\% CI: 1.1-2.4, but not for pressure sores (OR: $1.8 ; 95 \% \mathrm{CI}: 0.7-4.6$ ), and for urinary incontinence (OR: 3.3; 95\% CI: 0.9-12.0). All the other independent variables considered in the first model remained significantly associated with the events.

Since cognitive impairment was the most consistent independent variable associated with development of each event, we then evaluated the percentage of subjects with diagnosis of dementia at discharge: only $36.8 \%$ of subjects scoring $0-3$ at AMT had a diagnosis of dementia. The estimated population attributable risk percentage of an AMT score lower than 7 was $18.3 \%$ for pressure sores, $67.8 \%$ for fecal incontinence, $57.5 \%$ for urinary incontinence and $26.1 \%$ for falls.

\section{Discussion}

In this study, elderly people admitted to acute-care medical and geriatric wards proved to be an extremely frail population being, in almost half of the cases, moderately or severely disabled and, in a quarter of the cases, cognitively impaired and with a significant comorbidity. This study also provides evidence that specific diseases as well as specific drugs are associated with specific events, but, most of all, that conditions commonly observed in elderly people, such as cognitive and functional impairment, play a major and independent role in the development during hospitalization of some geriatric syndromes, such as pressure sores, fecal incontinence, urinary incontinence and falls. Finally, the oldest-old are the most susceptible group to any of the studied events. The interest of these latter data rely on the fact that very old people represent the group with an increased rate of hospital admissions: a survey of the GIFA study between 1988 and 1993 showed a 50\% increase in hospital admission of subjects aged 80 years and more [13].

Although previous researches reported that aging, cognitive impairment or disability increased the risk of medical injuries or adverse events during hospitalization [for a review, see 5], most of them analyzed a smaller number of patients or were focused only on one of the several outcomes considered in this study. The major strength of this study is its large sample size, the inclusion of many hospitals, thus increasing the generalization of the results, and the use of validated measures that are likely to be important predictors of the occurrence of the established events. In this study we used, as main outcomes, four hospital-acquired geriatric syndromes with the aim of detecting the factors more frequently associated with their development in elderly in-patients.

Very advanced age was associated with a greater risk of any event during the stay in hospital, independently of health status. This is conceivable with the aging-related impairment of compensatory mechanisms and increased susceptibility to any stressful factors related to hospitalization [14]. A severe disability was associated with a high risk of pressure sores and incontinence development, but it did not increase the risk of falling since, at this stage of functional impairment, patients are usually bedridden. Length of stay also increased the chance of development of geriatric syndromes during hospitalization, independently of physical, cognitive and functional impairment. It is biologically plausible that a long period of bed rest rapidly reduces the reserve capacity, due to decline in muscle strength and aerobic capacity, vasomotor instability, reduced bone density, altered sensory continence and reduced appetite [14]. All these factors may contribute to accelerate the functional decline and increase the risk of immobility and pressure sores, incontinence and falls.

Specific diseases were associated with increased risk of specific events. Cerebrovascular diseases increased the risk of both types of incontinence, probably due to reduced control on sphincter functions or to difficulties in going to the toilet [15]. Tumors were more associated with fecal incontinence, but we were not able to verify that the incontinence was due to the general severe conditions of these patients or to the specific type of tumor (for example, intestinal). Fractures increased the risk of pressure sores, as most of them were hip fractures with subsequent immobility.

A severe comorbidity, evaluated by means of the Charlson index, was found to be associated with an increased risk of fecal incontinence and falls.

A history of falls increased the risk of falling during the stay in hospital. These results are in agreement with previous studies that found that the rate of incidence of subsequent falls increased with the number of falls in community-dwelling [16] and hospitalized elderly subjects [17]. Although the risk factors for multiple fallers can be slightly different from one-time fallers [18], in hospitalized population a significant role seems to be played by the use of CNS active drugs [19]. Our study confirms these reports, as we found a significant increased risk of falls in subjects treated with neuroleptics and benzodiazepines. Among benzodiazepines, temazepam [20] as well as other very short and short half-life benzodiazepines [21] rep- 
resent important risk factors for falls in hospitals. Benzodiazepines were also reported to be associated with an increased risk of hip fracture in the elderly [22], although other researchers did not confirm this result [23]. The role of neuroleptics as an iatrogenic cause of falls in the elderly, however, has been less investigated, but these drugs seem to increase the risk of falls not only in the community but also in settings such as hospital and nursing home [24].

Prevalence of cognitive impairment in medical inpatients usually exceeds that in the general population, particularly in the oldest age group: in the present study it was $27 \%$, somewhat higher than in other studies of consecutively admitted medical inpatients [25]. The higher figure is probably due to our definition of cognitive impairment, that was based on a brief screening test (AMT) and not on a more detailed clinical diagnosis. In our population of elderly in-patients cognitive impairment was always significantly associated with an increasing risk of occurrence of all geriatric syndromes during hospitalization, showing how much cognitive disturbances per se represent a condition of increased frailty in a stressful environment such as an acute ward. In addition, we found that only $36.8 \%$ of subjects with a score of $0-3$ on AMT had a diagnosis of dementia at discharge. Although such a low score on the AMT scale is not sufficient for diagnosing dementia, the high discrepancy between the reported diagnosis and the test score suggests that cognitive impairment in hospitalized elderly patients is frequently underestimated. It is likely that cognitive functions are not always evaluated when the elderly are admitted to an acute ward where, quite often, the medical and nursing staff are more focused on treatment and management of acute diseases. So it is conceivable that a gap exists between the high prevalence of cognitive impairment in the hospitalized elderly population and its nondetection by the hospital staff, an aspect that deserves further investigation. Recently, it was shown that $3.9 \%$ of patients aged 60 and older admitted to a general hospital have a diagnosis of dementia [26] and that in hospitals employing programs of early screening and intervention [27] the length of stay and costs are reduced [28, 29]. In our study, about $20 \%$ of all new cases of pressure sores and falls and more than $50 \%$ of fecal and urinary incontinence were related to cognitive impairment. On the basis of these and our results, the screening and early identification of the elderly with cognitive impairment in the hospital should be emphasized, in order to detect subjects more at risk for those medical injuries which usually increase the length of stay as well as the cost of hospitalization, and markedly reduce the quality of life of elderly patients [30], with an increased risk of institutionalization or death after discharge.

There are some limitations to this study that must be acknowledged. Firstly, the GIFA clinical centers participated in the study on a voluntary basis; thus, this may not be a representative sample for all Italian hospitals. Secondly, in Italy the DRG system for reimbursement was introduced in 1995, a factor that could have reduced the length of stay compared to the previous surveys, especially for subjects suffering from less severe diseases.

In conclusion, in this study we found that very old people have a significant increased risk of developing geriatric syndromes during the stay in hospital, particularly if they are cognitively impaired and severely disabled. Since the elderly population is increasing, it is conceivable that in the near future this type of patients will be the most represented in hospital acute wards. Several risk factors can contribute to the occurrence of geriatric syndromes during hospitalization, so it is important to increase the knowledge in this field and to train medical and nursing staff for a prompt recognition of the preventable and manageable ones, in order to improve the quality of health care [31]. To this purpose, a more diffuse utilization of simple but effective risk assessment tools or request for appropriate documentation in the medical record [32-34] could be helpful in offering adequate responses - in terms of procedures, treatments and outcomes - to the extremely complex needs of elderly patients.

\section{Acknowledgments}

The authors thank Mrs. Joan Ireland Orfei for English revision. GIFA Study Group was partially supported by grant 94000402 from the National Research Council (CNR).

This study was presented in part as oral presentation at the 9th World Alzheimer Congress, Philadelphia, July 17-22, 2004. 


\section{References}

1 Becker P, McVey L, Saltz C, et al: Hospitalacquired complications in a randomized controlled clinical trial of a geriatric consultation team. JAMA 1987;257:2313-2317.

$\checkmark 2$ Brennan T, Leape L, Laird N, et al: Incidence of adverse events and negligence in hospitalized patients. Results of the Harvard Medical Practice Study. N Engl J Med 1991;324:370_ 376.

3 Covinsky K, Palmer R, Fortinsky R, et al: Loss of independence in activities of daily living in older adults hospitalized with medical illnesses: increased vulnerability with age. J Am Geriatr Soc 2003;51:451-458.

$\checkmark 4$ Lamont C, Sampson S, Matthias R, et al: The outcome of hospitalization for acute illness in the elderly. J Am Geriatr Soc 1983;31:282288.

$\checkmark 5$ Rothschild J, Bates D, Leape L: Preventable medical injuries in older patients. Arch Intern Med 2000;160:2717-2728.

6 Hoenig H, Rubenstein L: Hospital-associated deconditioning and dysfunction. J Am Geriatr Soc 1991;39:220-222.

7 Carosella L, Pahor M, Pedone C, et al: Pharmacosurveillance in hospitalized patients in Italy. Study design of the 'Gruppo Italiano di Farmacovigilanza nell'Anziano’ (GIFA). Pharmacol Res 1999;40:287-295.

$\checkmark 8$ Hodkinson H: Evaluation of a mental test score for assessment of mental impairment in the elderly. Age Ageing 1972;1:233-238.

$\checkmark 9$ Rocca W, Bonaiuto S, Lippi A, et al: Validation of the Hodkinson's abbreviated mental test as a screening instrument for dementia in an Italian population. Neuroepidemiology 1992;11: 288-295.

10 Charlson M, Pompei P, Ales KL, et al: A new method of classifying prognostic comorbidity in longitudinal studies: development and validation. J Chronic Dis 1987;5:373-383.

11 National Ulcer Advisory Panel: Pressure ulcers: incidence, economics, risk assessment. Consensus development conference statement. Decubitus 1989;2:24-28.

12 Moody H: Aging: Concepts and Controversies, ed 2. Thousand Oaks, Pine Forge, 1998.
13 Pahor M, Carosella L, Pedone C, et al: Trends of the characteristics and appropriateness of admission to acute geriatric and medical wards in Italy from 1988 through 1993. Eur J Epidemiol 1996;12:563-571.

14 Creditor M: Hazards of hospitalization in the elderly. Ann Intern Med 1993;118:219-223.

15 Harari D, Coshall G, Rudd A, et al: New-onset fecal incontinence after stroke: prevalence, natural history, risk factors, and impact. Stroke 2003;34:144-150.

16 Teno J, Kiel D, Mor V: Multiple stumbles: a risk factor for falls in community-dwelling elderly. A prospective study. J Am Geriatr Soc 1990;38:1321-1325.

17 Halfon P, Eggli Y, Van Melle G, et al: A. Risk of falls for hopitalized patients. A predictive model based on routinely available data. J Clin Epidemiol 2001;54:1258-1266.

18 Vassallo M, Sharma J, Allen S: Characteristics of single fallers and recurrent fallers among hospital in-patients. Gerontology 2002;48: 147-150.

19 Cumming R: Epidemiology of medication-related falls and fractures in the elderly. Drugs Aging 1998; 12:43-53.

20 Frels C, Williams P, Narayan S, et al: Iatrogenic causes of falls in hospitalised elderly patients: a case-control study. Postgrad Med 2002; 78:487-489.

21 Passaro A, Volpato S, Romagnoni F, et al: Benzodiazepines with different half-life and falling in a hospitalized population: the GIFA study. J Clin Epidemiol 2000;53:1222-1229.

22 Herings R, Stricker B, de Boer A, et al: Benzodiazepines and the risk of falling leading to femur fractures. Dosage more important than elimination half-life. Arch Intern Med 1995; 155:1801-1807.

23 Pierfitte C, Macouillard G, Thicoipe M, et al: Benzodiazepines and hip fractures in elderly people: case-control study. BMJ 2001;322: 704-708.
24 Leipzig R, Cumming R, Tinetti M: Drugs and falls in older people: a systematic review and meta-analysis. I. Psychotropic drugs. J Am Geriatr Soc 1999;47:30-39.

25 Erkinjuntti T, Wilkstrom J, Palo J, Autio L: Dementia among medical inpatients. Evaluation of 2000 consecutive admission. Arch Intern Med 1986;146:1923-1926.

26 Lyketsos C, Sheppard JME, Rabins P: Dementia in elderly persons in a general hospital. Am J Psychiatry 2000;157:704-707.

27 Landefeld C, Palmer R, Kresevic D, et al: A randomized trial of care in hospital medical unit especially designed to improve the functional outcomes of acutely ill older patients. $\mathrm{N}$ Engl J Med 1995;332:1338-1344.

28 Dinkel R, Lebok U: The effects of dementia in German acute care hospitals. Dement Geriatr Cogn Disord 1997;8:314-319.

29 Slaets J, Kauffmann RH, Duivenvoorden H, Pelemans W, Schudel WJ: A randomized trial of geriatric liaison intervention in elderly medical inpatients. Psychosom Med 1997;59:585591.

30 Sands LP, Yaffe K, Covinsky K, et al: Cognitive screening predicts magnitude of functional recovery from admission to 3 months after discharge in hospitalized elderly. J Gerontol Med Sci 2003:58A:37-45.

31 Schmader KE, Hanlon JT, Pieper CF, et al: Effects of geriatric evaluation and management on adverse drug rections and suboptimal prescribing in the frail elderly. Am J Med 2004; 116:394-401.

32 Oliver D, Britton M, Seed P, et al: Development and evaluation of evidence-based risk assessment tool (STRATIFY) to predict wich elderly inpatients will fall: case-control and cohort study. BMJ 1997;315:1049-1053.

33 Bennet R, O'Sullivan J, DeVito E, et al: The increasing medical malpractice risk related to pressure ulcers in the United States. J Am Geriatr Soc 2000;48:73-81.

-34 Perneger T, Rae A-C, Gaspoz JM, et al: Screening for pressure ulcer risk in an acute care hospital: development of a brief bedside scale. J Clin Epidemiol 2002;55:498-504. 